\title{
Changes in total body fat and body mass index among children with juvenile dermatomyositis treated with high-dose glucocorticoids
}

\author{
Amer Khojah ${ }^{1,2,3^{*}}$ (D) Victoria Liu ${ }^{3}$, Gabrielle Morgan ${ }^{3}$, Richard M. Shore ${ }^{4}$ and Lauren M. Pachman ${ }^{1,3}$
}

\begin{abstract}
Objective: High-dose glucocorticoids (GC) remain the primary therapy to induce remission in Juvenile Dermatomyositis (JDM). Studies of the natural history of GC associated weight gain in children are very limited, especially in the JDM population. This study aims to measure BMI changes in a cohort of JDM subjects over 60 months and to examine the changes in body composition by DXA.

Methods: We included all subjects with JDM who had 5 years of follow-up data and multiple DXA studies. BMI and total body fat (TBF) percentiles were calculated based on the CDC published percentile charts. To study the natural history of weight gain and TBF, we assessed the data at four-time points (T0 = baseline, $\mathrm{T} 1>1.5$ years, $\mathrm{T} 2=1.51-$ 3.49 years, $T 3=3.5-5$ years).

Results: 68 subjects (78\% female, 70\% white) were included in this retrospective study. Paired T-test showed a significant increase in the mean BMl percentile by 17.5 points $(P=0.004)$ after the initiation of medical treatment, followed by a gradual decrease over the study period. However, the TBF percentile did not change over the study period. TBF in the last visit (T3) had a strong correlation with the T1 BMI, and T1 TBF percentile (correlation coefficients $0.63,0.56 P<0.001,0.002$ respectively). Also, there was a positive correlation (correlation coefficients $0.39, P=0.002$ ) between the TBF percentile and muscle DAS but not the skin DAS.
\end{abstract}

Conclusions: Although the BMI percentile decreased throughout the study, the TBF percentile remained high until the end of the study (60 months). This finding raises the concern that some of the reduction in the BMI percentile could reflect a drop in the lean body mass from muscle wasting rather than actual fat loss.

Keywords: Juvenile dermatomyositis, Pediatric obesity, Glucocorticoids, DXA scan, And fat distribution

\section{Introduction}

Juvenile Dermatomyositis (JDM) is a multisystem pediatric disease characterized by chronic inflammation

\footnotetext{
*Correspondence: akhojah@luriechildrens.org; khojah.a@gmail.com

'Division of Pediatric Rheumatology, Department of Pediatric, Ann \& Robert

H. Lurie Children's Hospital of Chicago, Chicago, IL 60611, USA

${ }^{2}$ Division of Allergy \& Immunology, Ann \& Robert H. Lurie Children's Hospital of Chicago, Chicago, IL, USA

Full list of author information is available at the end of the article
}

of muscle and skin [1]. Despite the recent advances in the treatment of JDM, high dose corticosteroid remains the primary therapy to induce remission [2]. Typically, JDM patients need either intravenous or oral corticosteroid therapy for around 2 years [1]. Although previous studies showed that untreated JDM subjects have lower weight and height than age and gender-matched controls, [3] weight gain and cushingoid features are among the most common side effects observed in children after

(c) The Author(s). 2021 Open Access This article is licensed under a Creative Commons Attribution 4.0 International License, which permits use, sharing, adaptation, distribution and reproduction in any medium or format, as long as you give appropriate credit to the original author(s) and the source, provide a link to the Creative Commons licence, and indicate if changes were made. The images or other third party material in this article are included in the article's Creative Commons licence, unless indicated otherwise in a credit line to the material. If material is not included in the article's Creative Commons licence and your intended use is not permitted by statutory regulation or exceeds the permitted use, you will need to obtain permission directly from the copyright holder. To view a copy of this licence, visit http://creativecommons.org/licenses/by/4.0/ The Creative Commons Public Domain Dedication waiver (http://creativecommons.org/publicdomain/zero/1.0/) applies to the data made available in this article, unless otherwise stated in a credit line to the data. 
glucocorticoid initiation in various clinical trials [4]. Excessive weight gain has a negative impact on the affected child's physical and psychological well-being [5]. Youth obesity is associated with an increased risk of hypertension, type 2 diabetes mellitus, and hyperlipidemia, which are significant risk factors for future cardiovascular diseases [6]. Cardiovascular diseases are an important cause of mortality and morbidity in patients with inflammatory myopathy [7].

Besides corticosteroid therapy, there are other possible mechanisms of obesity in JDM subjects, such as; the lack of physical activity due to muscle weakness and metabolic changes from chronic inflammation [8, 9]. Long term studies of the natural history of corticosteroid associated weight gain in children are very limited, especially in the JDM population. Loss of muscle mass due to muscle inflammation and muscle ischemia may complicate the assessment of obesity and mask total gain in adipose tissue.

Dual-energy X-ray absorptiometry (DXA) has been used to measure various body composition, including body fat with high-precision and relatively low X-ray exposure $[10,11]$. JDM patients typically undergo routine DXA to measure the bone density due to their increased risk of pathological fractures from active inflammation, decrease mobility, and the chronic use of steroids [12]. The same DXA scan was used in this study to assess body composition, including total body fat, without additional financial burden to the patients or extra radiation. This study aims to measure body mass index (BMI) changes in a cohort of JDM subjects over 60 months duration and examine the body composition changes (fat vs. lean body mass) by DXA.

\section{Methods}

This was a retrospective chart review study conducted at The CureJM Center of Excellence in Juvenile Myositis Research and Care, Ann \& Robert H. Lurie Children's Hospital between 2000 and 2017 (IRB\# 2012-14,858). We included all JDM subjects who met Bohan and Peter criteria for definite or probable JDM diagnosis and had a minimum of 5 years of follow-up data with multiple DXA and BMI assessments during the study period. Subjects with overlap syndrome were excluded from the analysis. A GE-LUNAR iDXA bone densitometer was used to perform the DXA. Encore 16 software was used to analyzed DXA results and assess fat distribution among the various body part. The TBF (total body fat) percentile was calculated based on the Centers for Disease Control and Prevention (CDC) published TBF percentile charts from National Health and Nutrition Examination Survey (NHANES) [13].

The BMI percentile was calculated based on CDC published charts (https://www.cdc.gov/growthcharts/ clinical_charts.htm). Overweight was defined as a BMI at or above the 85th percentile and below the 95th percentile for age and gender-matched children. Obesity was defined as a BMI at or above the 95th percentile for age and gender-matched children. To study the natural history of weight gain and body fat changes, we assessed the patients' data at four-time point based on the duration of time between the date of first medication use and date of an assessment ( $\mathrm{T} 0=$ baseline, $\mathrm{T} 1>1.5$ years, $\mathrm{T} 2=1.51-3.49$ years, $\mathrm{T} 3=3.5-5$ years). Of note, if there is more than one assessment for a specific time point, we chose the closest to the optimal time point. For example, if a subject had DXA at 1.5 years and 2.5 years we only included the 2.5 years for T2 time point. We also evaluated disease activity markers on presentation such as skin, muscle weakness, and total Disease Activity Score (DAS) [14]. We defined disease course groups as following: 1-Monophasic: achieved remission without subsequent flares requiring reinitiation of treatment. 2Polyphasic: remission achieved within any length of time with at least one flare requiring treatment adjustment 3Chronic: failed to achieve remission and remain on treatment.

All statistical analyses were done IBM SPSS Statistics $26^{\circ}$ software. The paired T-test was used to compare the baseline BMI and TBF data and the subsequent time points. Person correlation analysis was used to assess the association between TBF percentile at the last visit of the study (3.5-5 years after medication onset) and disease activity markers and initial BMI. A $P$-value less than 0.05 was considered significant. The figures were generated using Graphpad Prism 8 software.

\section{Results}

Sixty-eight children with definite JDM were included in the study. The demographic data and disease subgroups by Myositis Specific Antibodies are available in Table 1. The mean age at enrolment was 6.97 years $(+/-3.4 \mathrm{SD})$. The mean duration of untreated disease was 6.7 months $(+/-8.4 \mathrm{SD})$. Disease course categories and metabolic complications were included in Table 2 . All study subjects received corticosteroid therapy, and many had multiple other immunosuppressive therapies during the study period (Table 1). The mean duration of oral corticosteroid in the study was 2.9 years $(+/-3.4 \mathrm{SD})$ and the mean number of IV steroid pulses for the subjects who received them was $29(+/-22 \mathrm{SD})$. BMI before the start of treatment revealed that only $16 \%$ of JDM patients were either overweight or obese. Of note, $53 \%$ of study subjects had BMI assessment before starting medications because the rest of the patients has received therapy before their initial assessment in our center. The mean time since the start of therapy for study visits was $0.96+/-0.4$ years, $2.56+/-0.4$ years, and $4.33+/-0.4$ 
Table 1 Demographic and disease characteristics of the study cohort

\begin{tabular}{|c|c|c|}
\hline & Frequency (n) & Percentage \\
\hline Sample size & 68 & \\
\hline \multicolumn{3}{|l|}{ Gender } \\
\hline Female & 54 & $79.4 \%$ \\
\hline Male & 14 & $20.6 \%$ \\
\hline \multicolumn{3}{|l|}{ Race/Ethnicity } \\
\hline White & 48 & $70.6 \%$ \\
\hline Hispanic & 10 & $14.7 \%$ \\
\hline African American & 6 & $8.8 \%$ \\
\hline Others & 4 & $5.9 \%$ \\
\hline \multicolumn{3}{|l|}{ Age } \\
\hline Less than 5 years & 26 & $38.2 \%$ \\
\hline More than 5 years & 42 & $61.8 \%$ \\
\hline \multicolumn{3}{|l|}{ Treatment status at 1st visit } \\
\hline Untreated & 36 & $52.9 \%$ \\
\hline Treated & 32 & $47.1 \%$ \\
\hline \multicolumn{3}{|l|}{ Myositis specific antibodies } \\
\hline P155/140 & 29 & $42.6 \%$ \\
\hline MJ & 5 & $7.2 \%$ \\
\hline Mi2 & 5 & $7.2 \%$ \\
\hline MDA5 & 2 & $2.9 \%$ \\
\hline Others or multiple MSAs & 1 & $1.5 \%$ \\
\hline Negative & 26 & $38.2 \%$ \\
\hline \multicolumn{3}{|l|}{ Treatment } \\
\hline Oral steroid & 68 & $100 \%$ \\
\hline Intravenous steroid & 60 & $88.2 \%$ \\
\hline Methotrexate & 66 & $97.1 \%$ \\
\hline Intravenous immunoglobulin & 14 & $20.6 \%$ \\
\hline Hydroxychloroquine & 28 & $41.2 \%$ \\
\hline Cyclosporin & 19 & $27.9 \%$ \\
\hline Mycophenolate & 43 & $63.2 \%$ \\
\hline
\end{tabular}

years for T1, T2, and T3, respectively. The majority of the children,for whom baseline BMI data were available, had a significant weight increase after treatment; 64\% were either in the overweight or obese category using the CDC definitions, and $30 \%$ of them were more than 98th percentile BMI for their age (Supplement Fig. 1). The baseline BMI Paired T-test showed a significant increase in the mean BMI percentile by 17.5 points $(P=$ 0.004) after the initiation of medical treatment (T1 time point) (Fig. 1). The average weight gain from baseline at the T1 time point was around $7.5 \mathrm{~kg}$ (mean weight at baseline $26.59 \mathrm{~kg}$, mean weight at T1 $34.13 \mathrm{~kg} P<0.001$ ). Unfortunately, most JDM subjects did not have DXA at baseline; therefore, assessing the change in the TBF from pretreatment was not done. Although the BMI
Table 2 Disease Course and complication of the study cohort

\begin{tabular}{|c|c|c|}
\hline & Frequency (n) & Percentage \\
\hline Sample size & 68 & \\
\hline \multicolumn{3}{|l|}{ Disease course } \\
\hline Monophasic & 43 & $63.2 \%$ \\
\hline Polyphasic & 12 & $17.6 \%$ \\
\hline Chronic & 12 & $17.6 \%$ \\
\hline \multicolumn{3}{|l|}{ Lipodystrophy (ever) } \\
\hline Present & 20 & $29.4 \%$ \\
\hline Absent & 48 & $70.6 \%$ \\
\hline \multicolumn{3}{|l|}{ Calcification (ever) } \\
\hline Present & 8 & $11.8 \%$ \\
\hline Absent & 60 & $88.2 \%$ \\
\hline \multicolumn{3}{|l|}{ History of fracture } \\
\hline Before the JDM diagnosis & 3 & $4.4 \%$ \\
\hline After the JDM diagnosis & 13 & $19.4 \%$ \\
\hline Absent & 51 & $76.1 \%$ \\
\hline \multicolumn{3}{|l|}{ Dyslipidemia } \\
\hline Acceptable Triglyceride level & 26 & $48.1 \%$ \\
\hline Borderline Triglyceride level & 11 & $20.4 \%$ \\
\hline High Triglyceride level & 17 & $31.5 \%$ \\
\hline Acceptable Total Cholesterol level & 32 & $59.3 \%$ \\
\hline Borderline Total Cholesterol level & 15 & $27.8 \%$ \\
\hline High Total Cholesterol level & 7 & $13.0 \%$ \\
\hline Acceptable LDL Cholesterol level & 37 & $72.5 \%$ \\
\hline Borderline LDL Cholesterol level & 7 & $13.7 \%$ \\
\hline High LDL Cholesterol level & 7 & $13.7 \%$ \\
\hline Acceptable HDL Cholesterol level & 32 & $61.5 \%$ \\
\hline Borderline HDL Cholesterol level & 8 & $15.4 \%$ \\
\hline low HDL Cholesterol level & 12 & $23.1 \%$ \\
\hline
\end{tabular}

percentile significantly decreased over the study period (Fig. 1), the TBF percentile did not change over the study period (Fig. 2, Supplement Fig. 2). TBF in the last visit (T3) had a strong correlation with the T1 BMI, and T1 TBF percentile (correlation coefficients 0.63, 0.56 $P<0.001,0.002$ respectively) (Supplement Fig. 3). Interestingly, there is a positive correlation between the TBF percentile at T3 and muscle DAS (correlation coefficients $0.49, P=0.001$ ) (Supplement Fig. 4) but not with the skin DAS (correlation coefficients $-0.08, P=0.61$ ). Also, there was a negative correlation between CMAS (Childhood Myositis Assessment Scale) and TBF percentile at T3 (correlation coefficients $-0.42, P=0.027$ ). Of note, there was no significant correlation between the duration of oral corticosteroid therapy and BMI or TBF percentile. 


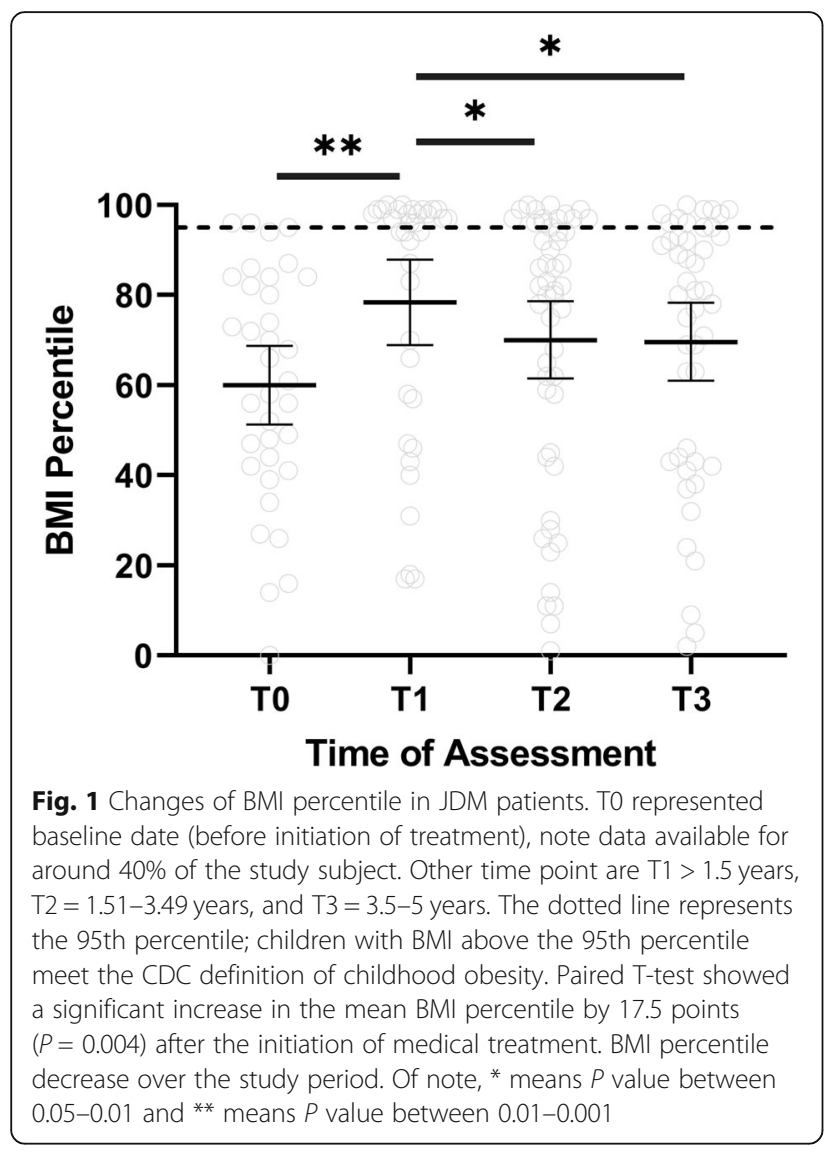

\section{Discussion}

Although most JDM patients had a normal BMI before starting medication, $70 \%$ met the CDC definition of overweight or obese in the first data point of the study $(0.95+/-0.4$ years after treatment initiation). This rapid

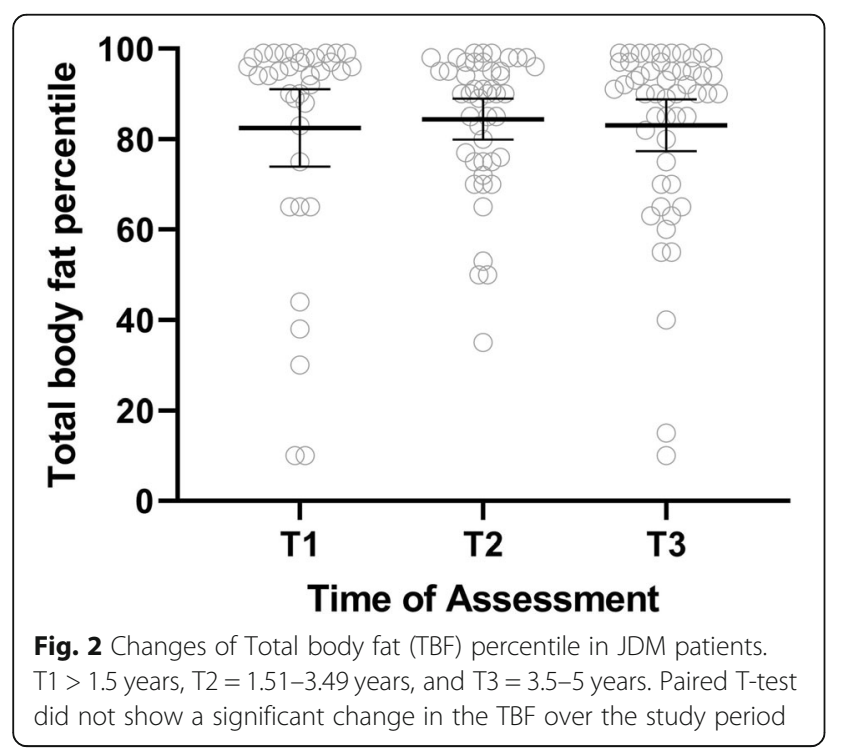

increase in the patient's weight is likely due to corticosteroid therapy, physical inactivity, and changes in adipokine levels due to their inflammatory status $[4,8,15]$. Although the BMI percentile improves over the study period, it did not reach pretreatment level even 4.5 years after the start of therapy. This highlights the importance of preventing excessive weight gain as soon as a patient gets started on chronic corticosteroid with early institution of exercise and healthy eating habits. Of note, the percentage of children with calcifications was $11 \%$, which is less than the current national level 13.3\% [1]. Unfortunately, in our study, we could not assess the extent of their physical activity and adipokine due to the study's retrospective nature. Although we could not measure the exact accumulative dose of corticosteroid, most patients in our study had prolonged oral steroid courses with a mean duration of oral steroid around 3 years and multiple IV steroid courses. The typical treatment plan of JDM patient in our center involves a minimum of 3 days of IV methylprednisolone pulse (30 $\mathrm{mg} / \mathrm{kg}$ with maximum dose $1000 \mathrm{mg}$ ) on admission followed by weekly IV methylprednisolone pulses with small doses of oral steroids (typically $0.5 \mathrm{mg} / \mathrm{kg} /$ day of prednisolone), which were weaned over time base the disease's activity. Of note, seven subjects (five of them were managed in other centers initially) did not receive IV steroid therapy in our cohort. These subjects had lower DAS (6.6 vs $12 P<0.001)$, lower Neopterin $(10.2$ vs $19 P=0.08$ ) and higher CMAS (43.7 vs $30.4 P=0.03$ ). Even though steroid-sparing agents such as methotrexate, mycophenolate, and IVIG are typically started early on, our JDM patients generally are treated with glucocorticoids for at least 1-2 years. This significant corticosteroid exposure can lead to an increased risk of side effects such as weight gain, glaucoma, cataracts, and vertebral fracture. Our patients usually get DXA annually to monitor bone density. The same DXA scan was used in this study to assess body composition, including total body fat, without additional financial burden to the patients or extra radiation. Assessing body composition by DXA revealed a higher percentage of total body fat than the age-matched peers evident by the high total body fat percentile based on the NHANES [13], in addition to the significant weight gain after starting corticosteroid. Furthermore, the mean TBF percentile did not show a statistically significant change over the study period despite decreasing the mean BMI percentile. This finding raises the concern that some of the reduction in the BMI percentile could reflect a drop in the lean body mass from muscle wasting rather than actual fat loss.

This study has some limitations, including lack of baseline DXA scan;47\% of the subjects received treatment before getting referred to our center, and the lack of quantitation of the extent of their physical activity 
and adipokine measurement. Despite these limitations, the study sheds light on the risk of childhood adiposity after chronic corticosteroid exposure. We hope this study will inspire more research in this area and eventually lead to more intervention-based research to prevent weight gain and excess body fat gain when treating patients with autoimmune diseases.

\section{Conclusion}

Children with Juvenile Dermatomyositis develop significant weight gain in the first year of therapy, evident by the sharp increase in the BMI percentile. Although the BMI percentile decreased throughout the study after the initial spike, the TBF percentile remained high until the end of the study (60 months).

\section{Abbreviations}

GC: Glucocorticoids; JDM: Juvenile Dermatomyositis; BMI: Body Mass Index; TBF: Total body fat; DXA: Dual-energy X-ray absorptiometry; CDC: Centers for Disease Control and Prevention; NHANES: National Health and Nutrition Examination Survey; DAS: Disease Activity Score; IBM SPSS: International Business Machines Corporation Statistical Package for the Social Sciences

\section{Supplementary Information}

The online version contains supplementary material available at https://doi. org/10.1186/s12969-021-00622-1

Additional file 1: Fig. 1s: Changes of BMI percentile in JDM patients over study duration (60 months). T0 represented baseline date (before initiation of treatment), note data available for around $53 \%$ of the study subject. Other time point are $\mathrm{T} 1>1.5$ years, $\mathrm{T} 2=1.51-3.49$ years, and $\mathrm{T} 3=$ 3.5-5 years. The BMI percentile was calculated based on CDC published charts (https://www.cdc.gov/growthcharts/clinical_charts.htm). Overweight was defined as a BMl at or above the 85th percentile and below the 95th percentile for age and gender-matched children. Obesity was defined as a BMI at or above the 95th percentile for age and gender-matched children and divided into two groups based on severity.

Additional file 2: Fig. 2s: Changes of Total body fat (TBF) percentile in JDM patients over study duration (60 months). T1 $>1.5$ years, $\mathrm{T} 2=1.51$ 3.49 years, and $\mathrm{T} 3=3.5-5$ years.

Additional file 3: Fig. 3s: Correlation between Total body fat (TBF) percentile at the last visit (T3) and BMI percentile at T1. There was a positive correlation between T1 BMI, and T3 TBF percentile (correlation coefficients $0.63, P<0.001$ )

Additional file 4: Fig. 4s: Correlation between Total body fat (TBF) percentile at the last visit (T3) and initial muscle DAS. There was a positive correlation between TBF percentile at T3 and initial muscle DAS (correlation coefficients $0.49, P=0.001$ ).

\section{Acknowledgements}

None.

\section{Authors' contributions}

All authors have contributed to the manuscript. Conception and design: Amer Khojah, Richard Shore, Lauren Pachman. Acquisition of data: Victoria Liu, Gabrielle Morgan. Analysis and interpretation of data: Amer Khojah, Richard Shore, Lauren Pachman. Manuscript writing and review Amer Khojah, Victoria Liu, Gabrielle Morgan, Richard Shore, Lauren Pachman. The author(s) read and approved the final manuscript.

\section{Funding}

Supported in part by the CureJM Foundation Center of Excellence; R-21 AR077565 both to (LMP). The data in this project is entered in REDCap which is supported by NUCATS, and funded in part by a Clinical and Translational
Science Award (CTSA) grant from the National Institutes of Health (NIH),UL1TR001422.

Availability of data and materials

3 supplement figures

\section{Declarations}

Ethics approval and consent to participate

Authors have obtained the required ethical approvals and have given the necessary attention to ensure the integrity of the work. IRB\# 2012-14858 at Ann \& Robert H. Lurie Children's Hospital.

\section{Consent for publication}

The final manuscript has been reviewed and approved by all the authors.

\section{Competing interests}

There is no potential conflict of interest, real or perceived by any of the authors.

\section{Author details}

${ }^{1}$ Division of Pediatric Rheumatology, Department of Pediatric, Ann \& Robert H. Lurie Children's Hospital of Chicago, Chicago, IL 60611, USA. Division of Allergy \& Immunology, Ann \& Robert H. Lurie Children's Hospital of Chicago, Chicago, IL, USA. ${ }^{3}$ Cure JM Center of Excellence, Stanley Manne Research Center, Chicago, IL, USA. ${ }^{4}$ Department of Medical Imaging, Ann \& Robert $\mathrm{H}$. Lurie Children's Hospital of Chicago, Chicago, IL, USA.

Received: 25 April 2021 Accepted: 3 July 2021

Published online: 10 August 2021

\section{References}

1. Pachman LM, Nolan BE, DeRanieri D, Khojah AM. Juvenile Dermatomyositis: New Clues to Diagnosis and Therapy. Curr Treat Options in Rheum. 2021;7: 39-62. https://doi.org/10.1007/s40674-020-00168-5.

2. Pachman LM, Khojah AM. Advances in juvenile dermatomyositis: myositis specific antibodies aid in understanding disease heterogeneity. J Pediatr. 2018;195:16-27. https://doi.org/10.1016/j.jpeds.2017.12.053.

3. Pachman LM, Abbott K, Sinacore JM, Amoruso L, Dyer A, Lipton R, et al. Duration of illness is an important variable for untreated children with juvenile dermatomyositis. J Pediatr. 2006;148(2):247-53. https://doi.org/10.1 016/j.jpeds.2005.10.032.

4. Aljebab F, Choonara I, Conroy S. Systematic review of the toxicity of longcourse Oral corticosteroids in children. PLoS One. 2017;12(1):e0170259. https://doi.org/10.1371/journal.pone.0170259.

5. Pulgaron ER. Childhood obesity: a review of increased risk for physical and psychological comorbidities. Clin Ther. 2013;35(1):A18-32. https://doi.org/1 0.1016/j.clinthera.2012.12.014

6. Levin A, Morad Y, Grotto I, Ravid M, Bar-Dayan Y. Weight disorders and associated morbidity among young adults in Israel 1990-2003. Pediatr Int. 2010;52(3):347-52. https://doi.org/10.1111/j.1442-200X.2009.02972.x.

7. Gupta R, Wayangankar SA, Targoff IN, Hennebry TA. Clinical cardiac involvement in idiopathic inflammatory myopathies: a systematic review. Int J Cardiol. 2011;148(3):261-70. https://doi.org/10.1016/j.ijcard.2010.08.013.

8. Takken T, Spermon N, Helders PJ, Prakken AB, Van Der Net J. Aerobic exercise capacity in patients with juvenile dermatomyositis. J Rheumatol. 2003;30(5):1075-80.

9. Huemer C, Kitson H, Malleson PN, Sanderson S, Huemer M, Cabral DA, et al. Lipodystrophy in patients with juvenile dermatomyositis--evaluation of clinical and metabolic abnormalities. J Rheumatol. 2001;28(3):610-5.

10. Gotfredsen A, Jensen J, Borg J, Christiansen C. Measurement of lean body mass and total body fat using dual photon absorptiometry. Metabolism. 1986;35(1):88-93. https://doi.org/10.1016/0026-0495(86)90101-0.

11. Khojah A, Liu V, Savani SI, Morgan G, Shore R, Bellm J, et al. Studies of 96 children with juvenile dermatomyositis: P155/140, is associated with loss of nailfold capillaries, but not generalized lipodystrophy. Arthritis Care Res. 2020. https://doi.org/10.1002/acr.24535.

12. Castro TC, Terreri MT, Szejnfeld VL, Len C, Fonseca AS, Hilario MO. Bone mineral density of Brazilian girls with juvenile dermatomyositis. Braz J Med Biol Res. 2005;38(2):309-13. https://doi.org/10.1590/S0100-879X20050002 00020 . 
13. Ogden CL, Li Y, Freedman DS, Borrud LG, Flegal KM. Smoothed percentage body fat percentiles for U.S. children and adolescents, 1999-2004. Natl Health Stat Report. 2011(43):1-7.

14. Bode RK, Klein-Gitelman MS, Miller ML, Lechman TS, Pachman LM. Disease activity score for children with juvenile dermatomyositis: reliability and validity evidence. Arthritis Rheum. 2003;49(1):7-15. https://doi.org/10.1002/a rt.10924.

15. Olazagasti JM, Hein M, Crowson CS, de Padilla CL, Peterson E, Baechler EC, et al. Adipokine gene expression in peripheral blood of adult and juvenile dermatomyositis patients and their relation to clinical parameters and disease activity measures. J Inflamm (Lond). 2015;12:29.

\section{Publisher's Note}

Springer Nature remains neutral with regard to jurisdictional claims in published maps and institutional affiliations.

Ready to submit your research? Choose BMC and benefit from:

- fast, convenient online submission

- thorough peer review by experienced researchers in your field

- rapid publication on acceptance

- support for research data, including large and complex data types

- gold Open Access which fosters wider collaboration and increased citations

- maximum visibility for your research: over $100 \mathrm{M}$ website views per year

At $\mathrm{BMC}$, research is always in progress.

Learn more biomedcentral.com/submissions 